\title{
DA CITAÇÃO COMO TRADUÇÃO E CRÍTICA NA OBRA DE MACHADO DE ASSIS
}

\author{
Eliane Fernanda Cunha
}

*Eliane Fernanda Cunha é professora Titular de Teoria Literária no curso de Letras do Centro Universitário da Grande Dourados (UNIGRANMS). Doutora em Literatura Comparada pela UFMG.

\begin{abstract}
RESUMO: Analysis of the use of citations (both translated and not) as a criticism, was an integral part of the intellectual and literary formation of the writer-translator Machado de Assis. The translation of fragments of foreign texts demonstrates the important role exercised by the translator's task, not only in Machado's literary career, but also reveals the cultural context of 19th century Brazilian society. Translation within a comparative framework contributed to the flowering of a sense of self and other and served as a fundamental piece of the translated/intertextual Machadian mosaic.
\end{abstract}

PALAVRAS-CHAVE: Machado de Assis. Estudos de Tradução. Literatura Comparada. Citação. Crítica. Intertextualidade.

A primeira função da tradução (e papel dos tradutores) é fazer circular um texto fora da literatura de origem, disseminá-lo, difundi-lo. O tradutor, por vezes, designado de "barqueiro" (ele atravessa um rio), possibilita o acesso não só a uma obra literária gerada em outra língua, mas a costumes e princípios que o texto, traduzido, veicula.

Tânia Carvalhal, 2003

Assim como século XX foi decisivo para a institucionalização da Literatura Comparada como disciplina acadêmica e área do conhecimento, concomitantemente, os Estudos de Tradução também vêem se institucionalizando, na medida em que já conquistaram um espaço significativo nos cursos de Letras tanto em nível de graduação quanto de Pós-Graduação lato e stricto sensu. Haja vista a criação do primeiro curso de pós-graduação stricto sensu em Estudos da Tradução, já no século XXI, em 2003, na Universidade Federal de Santa Catarina, como reflexo do rápido desenvolvimento das reflexões acerca da teoria da tradução nos meios acadêmicos dos cursos de Letras. Além disso, a Universidade Gama Filho (Rio de Janeiro) tem oferecido o curso de Especialização em tradução de espanhol/português - português/espanhol. A Faculdade Ibero-Americana (São Paulo), além dos excelentes cursos na área, vem promovendo desde 1998 o Congresso (internacional) Ibero-Americano de Tradução e Interpretação (CIATI), que reúne pesquisadores do mundo todo. A Associação Brasileira de Pesquisadores em Tradução (ABRAPT), fundada pelo Prof. Dr. Mário Laranjeira, em maio de 1994, e o Centro Interdepartamental de Tradução e Terminologia da USP (CITRAT) têm promovido encontros sobre tradução, sendo o primeiro internacional realizado em 1998, além de cursos de Especialização. Grupos de pesquisa estão cadastrados no CNPq, cursos de bacharelado em "Tradutor e intérprete" têm se proliferado nos cursos de Letras de todo o país, ampliando o mercado de trabalho para a área. No último congresso internacional da Associação Brasileira de Literatura Comparada, realizado na Universidade Federal do Rio Grande do Sul, em julho de 2004, o simpósio "Embarcações tradutórias", que homenageou o almirante-mor da tradução, Haroldo de Campos, reuniu pesquisadores da América Latina, Estados-Unidos, Canadá e Europa. Esse mapeamento do local que a tradução vem conquistando na república mundial das letras delineia um traço mais acentuado na América Latina, onde vamos encontrar escritores-tradutores como Jorge Luis Borges, Haroldo de Campos, Julio Cortázar, Carlos Drummond de Andrade, Raquel de Queiroz e Machado de Assis, que pela prática da tradução elaboraram pensamentos, críticas e teorias sobre esse ofício tão antigo quanto a literatura. Percebe-se, portanto, que o traduzir faz parte do percurso literário desses escritores.

Observa-se que a Literatura Comparada ingressava nos cursos de Letras no Brasil pelo viés da teoria literária enquanto os Estudos de Tradução se ingressavam pelo dos estudos comparatistas. Tanto nos estudos comparatistas quanto nos de tradução, as antigas noções de fontes e influências, que alicerçavam ambos os estudos, foram redimensionados. Na Literatura Comparada, o conceito operatório da crítica - a intertextualidade - passou a ser o elemento crucial para se refletir sobre a prática comparatista, juntamente com a interculturalidade e a interdisciplinaridade, que formam o tripé que sustenta os estudos comparados, considerando que estes exploram "relações não apenas entre textos e autores ou culturas, mas se ocupa com questões que decorrem do confronto entre o literário e o não-literário, entre o fragmento e a totalidade, entre o similar e o diferente, entre o próprio e o alheio." (CARVALHAL, 2003, p. 11). E é nesse contexto tridimensional que a tradução se insere, já que esta é um dos componentes do diálogo entre os textos, sendo considerada até como sinônimo de intertextualidade, conforme 
afirmam as autoras do livro Intertextualidades: teoria e prática (1994) - Graça Paulino, Ivete Walty e Nazareth Fonseca. Enquanto um texto não for traduzido para a língua de um outro país, ele não passa a integrar o sistema literário. "A tradução tem um papel decisivo na transmissão das influências literárias." (CARVALHAL, 2003, p. 230), bem como "é fator não apenas de difusão de textos em processos interliterários, mas é também um elemento iluminador dos procedimentos criativos e receptivos" (CARVALHAL, 2003, p. 258).

Como implantadoras dos estudos comparatistas no Brasil, cita-se Tânia Carvalhal (UFRGS), primeira presidente da ABRALIC (1986-1988) e Eneida Maria de Souza (UFMG), a segunda (1988-1990). Ambas continuam a atuar ativamente. A ensaísta gaúcha tem implantado os Estudos Comparatistas em outros países da América Latina, e foi eleita, recentemente, no dia 10 de agosto de 2004, presidente da Associação Internacional de Literatura Comparada, em Hong Kong. A professora e crítica cultural mineira tem se dedicado à crítica cult, mais próxima dos Estudos Culturais, o que não exclui a Literatura Comparada já que também a vertente culturalista entrelaça-se com a comparatista. Tanto Souza quanto Carvalhal, em suas últimas publicações - Crítica Cult (2002) e $O$ próprio e o alheio: ensaios de literatura comparada (2003) - ao reunirem seus ensaios mais significativos de suas produções ensaísticas são unânimes em reconhecer o importante lugar que os Estudos de Tradução passaram a ocupar nos Estudos Literários em geral e mais especificamente na Literatura Comparada..

Em seu ensaio "O espaço nômade do saber", Eneida Maria de Souza demonstra o início da reflexão teórica sobre tradução no Brasil através dos estudos semióticos do poeta, crítico e tradutor, Haroldo de Campos, pautado na aproximação entre tradução e antropofagia, decorrente da associação com a intertextualidade e com vistas a uma perspectiva sincrônica em relação à tradição cultural brasileira (SOUZA, 2002, p. 42), "ao se retomar o projeto artístico oswaldiano e recolocar a problemática de nossa literatura (da América Latina e do Terceiro Mundo em geral) enquanto "tradutora" da cultura do Outro" (SOUZA, 1993, p. 36 ).

Mas antes de Haroldo de Campos, vamos encontrar em Borges e mais ainda em Machado de Assis a prática da tradução e reflexões sobre essa. Machado, intertextual avant la lettre, começou sua carreira literária pela tradução. Os escritores latino-americanos, ao terem como ponto de referência a cultura européia, tiveram por um longo período aquela "mirada estrábica", que Ricardo Piglia tão bem definiu o posicionamento do intelectual latino-americano, ao se referir à obra de Borges, que mantinha "um olho dirigido para a inteligência européia e outro para as entranhas da pátria" (SOUZA, 2002, p. 45), atentando para "a transformação gradativa dos centros hegemônicos e a permanente mobilidade das transferências culturais que contribuem para a releitura de diferentes alvos contidos no conceito de "mirada estrábica". Julio Cortázar aconselhava aos novos poetas que praticassem a tradução de bons poetas, pois este exercício, ao propiciar o contato com o alheio, acabaria por gerar o encontro do seu próprio caminho (texto). E assim foi com Dante Alighuieri, Borges, Machado de Assis, Drummond, Raquel de Queiroz, Monteiro Lobato e tantos outros escritores (ras) que foram ou são tradutores (ras). Os escritores latino-americanos sempre viveram em um espaço de tensão entre o próprio e o alheio na construção da formação de uma identidade nacional, e a tradução, sem dúvida, foi um importante elemento nesse processo, considerando que "traduzir, transformar, deformar, recriar são, pois, procedimentos nucleares do processo de formação e de consolidação dessas literaturas." (CARVALHAL, 2003, p. 20 ). Pois como já pensava Göethe (1827) em seu conceito de Weltliteratur, a tradução é imprescindível para o reconhecimento do próprio. Segundo Pascale Casanova (2002), analisando o pensamento tradutório de Göethe, "ele via no tradutor um ator central" não apenas do intercâmbio de interesses econômicos ou nacionalistas mas igualmente como criador de "valor" literário, que assim dizia que cada tradutor deveria ser considerado "como um mediador que se esforça por promover esse intercâmbio espiritual universal e que se impõe como tarefa fazer esse comércio generalizado progredir. Por mais insuficiente que seja a tradução, essa atividade continua sendo uma das tarefas mais essenciais e dignas de estima do mercado de intercâmbio mundial universal.' (GÖETHE apud CASANOVA, 2002, p. 28-29).

Embora até aqui tem-se tentado demonstrar o lugar que a tradução tem ocupado nos estudos comparatistas, verifica-se, por parte de alguns professores de Literatura Comparada, uma resistência e até mesmo uma indiferença para com os Estudos de Tradução, na medida em que em seus conteúdos programáticos não contemplam a teoria da tradução e não citam os nomes dos tradutores nas referências bibliográficas. Aliás, a negligência das fontes, em geral, e em especial as referentes às traduções nos trabalhos acadêmicos dos cursos de graduação e de pós-graduação é uma triste realidade. Não se deve perder de vista que foi um processo longo de luta dos tradutores para que seus nomes fossem citados nas referências bibliográficas, afinal, sem a tradução, principalmente de textos teóricos, tanto professores quanto alunos ficariam prejudicados em seus estudos e pesquisas, já que a maioria dos autores que lemos e adotamos são estrangeiros.

A simples constatação de que o ensaio mais extenso da coletânea de ensaios de Tânia Carvalhal intitulada $O$ próprio e o alheio: ensaios de literatura comparada (2003) é dedicado à reflexão sobre o papel da tradução exercido dentro dos estudos comparatistas já denota a importância que essa prática, tão antiga quanto a literatura, tem ocupado 
nas pesquisas contemporâneas não só relativas aos estudos comparatistas, mas também na historiografia literária e na Teoria da Literatura.

Nas quarenta e duas páginas de seu ensaio - "Tradução e recepção na prática comparatista" - , Carvalhal retoma, como ela mesma esclarece, "questões de recepção e disseminação literárias sem desvincular tradução e tradição", procurando acentuar a importância das traduções nos processos de relações intra e interliterárias, como recurso indispensável ao conhecimento do Outro, reconhecido em sua diferença e de outras culturas (CARVALHAL, 2003, p. 10).

Com os estudos comparatistas, a tradução deixou de ser entendida apenas como uma prática interlingual, de conotação lingüística de trasladar um texto de uma língua para outra. Pode-se afirmar que a obra de Georges Mounin - Os problemas teóricos da tradução (1963) - foi o texto fundador que suscitou um outro olhar para a prática da tradução, muito embora tenda para o momento estruturalista da época na França, mas já vislumbrando um outro caminho para a tradução, considerada até então uma "arte secundária e derivativa" (CARVALHAL, 2003, p. 219), inferior, subalterna, presa aos preceitos teóricos de fidelidade, sendo o tradutor, além de invisível, um traidor, quando não buscava a equivalência lexical impossível.

No Brasil, à época em que o livro de Mounin foi publicado na França, Haroldo de Campos estava publicando o seu já clássico ensaio - "Da tradução como criação e como crítica" (1962), no qual se discute a pertinência da tradução literal e se defende a criatividade do tradutor. Poundianamente, Haroldo de Campos incorpora o leme do "make it new" pela via da tradução, vista como uma maneira de "dar nova vida ao passado literário" (CAMPOS, 1992, p. 36). Desde Pound, a tradução passou a ser entendida como recriação, reivindicando uma "categoria estética da tradução como criação", conforme análise de Campos (1992, p. 35). Dessa forma, os estudos de tradução desenvolvidos a partir dos anos 1970 proclamaram um estatuto próprio para a tradução. O entendimento de toda tradução literária como um ato criativo abre caminho para novas posições, que têm em conta a natureza criadora do ato de traduzir e seus aspectos contextuais e que, além disso, compreendem a tradução como um ato de comunicação e de intermediação entre culturas (CARVALHAL, 2003, p. 219).

No Brasil oitocentista, a tradução ocupava um lugar de destaque na capital imperial, pois, como a única atividade cultural era ir ao teatro, as peças teatrais, em sua maioria advindas do repertório francês, eram traduzidas para representação nos palcos fluminenses. Daí as traduções ficarem a cargo de qualquer um que entendesse a língua francesa, pois como o público que freqüentava as casas de espetáculo era o mesmo, o repertório precisava ser variado e com isso os empresários teatrais, como João Caetano, precisavam dos textos traduzidos "a toque de caixa". Tal situação não agradava a Machado de Assis, que foi tradutor de peças teatrais francesas, além de ter sido parecerista do Conservatório Dramático Brasileiro, quando criticava o descuido dos tradutores com a língua portuguesa. ${ }^{i}$

No início de sua carreira literária, Machado de Assis praticou, veementemente, a tradução de peças teatrais francesas e de poesias, além do romance Os trabalhadores do mar de Victor Hugo, do ensaio satírico de Victor Hénaux - Queda que as mulheres têm para os tolos -, perfazendo um total de quarenta e oito traduções. Essa atividade acompanhou seu percurso literário, estando intrínseca à sua formação intelectual. Como a tradução é um dos tipos de intertextualidade presentes na produção literária e como a inter-relação textual é um sinônimo para Literatura Comparada, logo, Machado, pela via da tradução, pouco trilhada pelos estudiosos machadianos, foi um comparatista avant la lettre.

Uma das contribuições relevantes que aflora da obra machadiana para a questão da tradutologia é o uso de citações em língua estrangeira ou em tradução de trechos de autores pertencentes ao cânone ocidental como Molière, Shakespeare, Dante, dentre outros.

Segundo Antoine Compagnon, o trabalho de citação é o de evidenciar o processo intertextual efetivado pelos escritores. Por meio das citações, traça-se um perfil das leituras feitas pelos produtores de textos. "A mola do trabalho da citação é uma paixão pelo fenômeno, pelo working ou o playing, pelo manejo da citação" (COMPAGNON, 1996, p. 34). E é desta maneira que Machado de Assis, como escritor latino-americano, "brinca" com o cânone, com a tradição literária ocidental. Ao citar em tradução ou não, ele, ao mesmo tempo em que desconstrói seus 'pais literários', reverencia-os,

No trabalho de citação, o escritor é um manobrista do fazer recortes e colagens. A noção essencial da citação é a de jogo, como se demonstrará nos exemplos retirados das crônicas machadianas, já que ele escreveu mais de seiscentas. Nesse sentido, a citação funciona também como reescrita porque, "escrever, pois, é sempre reescrever, não difere de citar. A citação, graças à confusão metonímica a que preside, é leitura e escrita, une o ato de leitura ao de escrita", segundo Compagnon (1996, p. 31). Por meio da citação, o escritor exercita o ato da apropriação. Ao se apossar de um texto alheio, o escritor precisa apropriar-se dele, para livrar-se do sentido de alienação que permeia tal ato, por remeter-lhe a noção de "roubo". Para o próprio Machado o legado literário universal estaria à disposição da humanidade, declarando, quatro anos antes da publicação de Dom Casmurro, que se "a Revolução Francesa e Otelo estão feitos; nada impede que esta ou aquela cena seja tirada para outras peças, e assim se cometem, literariamente 


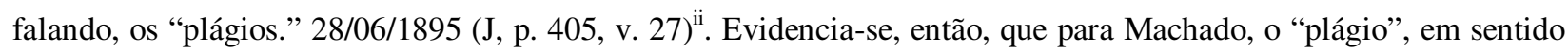
figurado, sempre foi uma prática dos escritores, que ao citarem outros "confrades de versos" acabam se considerando os inventores dos textos que escrevem, conforme uma das reflexões de um relojoeiro: "Citar a propósito um texto alheio, equivale a tê-lo inventado". E mais, que "O melhor meio de compreender a alma universal do ser humano era através do estudo de grandes escritores mundiais; o melhor meio de retratá-los era "plagiá-los" (MACHADO DE ASSIS apud CALDWELL, 1960, p.165). iii

Baseando-se nos Essais, de Montaigne, Compagnon afirma que esses "são uma busca do sujeito no desfile dos objetos que o retêm tanto ou mais do que eles são retidos", concluindo que "apropriar-se seria menos tomar que se retomar, menos tomar posse de outrem que de si" (COMPAGNON, 1996, p. 94). É dessa forma que Machado constituiu-se como tradutor e elaborou uma teoria sobre tradução. Ao apropriar-se de textos alheios para traduzir, formulava concomitantemente uma teoria sobre o traduzir. Molière foi um dos autores teatrais preferidos de Machado de Assis, que era apaixonado por teatro. A peça Le Mèdecin malgré lui, traduzida por ele, foi citada em diversos textos de sua produção literária. Dessa maneira, a citação como tradução pode ser analisada de acordo com o conceito de "segunda mão", de Compagnon. Para o ensaísta francês, a citação funciona como uma moldura do pensamento do escritor, em que se podem detectar suas preferências literárias. As várias citações que Machado faz de alguns diálogos de peças do dramaturgo francês, além de evidenciarem a preferência do autor por este escritor teatral, demonstra também a sua crítica à presença, por exemplo, da medicina e das ciências positivistas na sociedade brasileira oitocentista. Com ironia, através das citações, Machado desconstruia o status quo da profissão liberal que passava a substituir uma tarefa, a de cura, por exemplo, até então exercida pelos padres. Em seus textos, a citação exerce uma função crítica. A citação das traduções é a geradora dos textos do cronista, dando-lhes sentido, que, segundo Compagnon, "vem por acréscimo, ele é o suplemento do trabalho" (COMPAGNON, 1996, p. 34).

O uso da citação de autores estrangeiros, no original ou em tradução, suplementava o assunto das crônicas, dos contos, das poesias e dos romances em que os textos foram produzidos. Eis alguns exemplos:

a) No conto "Capítulo dos chapéus", um diálogo da peça de Molière serviu de epígrafe:

\section{GERONTE}

Dans quel chapitre, s'il vous plait?

SGANARELLE

Dans le chapitre des chapeaux.

Molière (J, p. 105, v. 13);

b) Em crônica de 14 de agosto de 1864, escrita para o Diário do Rio de Janeiro, Machado traduz algumas

falas dessa peça de Molière para ridicularizar o ministro, Sr. Zacarias:

SGANARELLO.

... vossa filha está muda.

GERONTE.

Sim, mas eu quisera saber donde provém isso.

SGANARELLO.

Não há nada mais fácil; provém de ter perdido a palavra.

GERONTE.

Muito bem; mas a causa que lhe fez perder a palavra?

SGANARELLO.

Os nossos melhores autores dir-vos-ão que é o impedimento da ação da língua.

GERONTE.

Mas qual é vossa opinião sobre este impedimento da ação da língua?

SGANARELLO.

Aristóteles diz a este respeito... coisas muito bonitas!” (J, p. 95-96, v. 23).

Sobre essa tradução, Massa fez as seguintes observações:

Em 14 de agosto de 1864, Machado de Assis integra a uma crônica política a tradução do célebre diálogo entre Géronte e Sganarelle onde este explica, à luz de Aristóteles, a mudez de Lucinda. Desta forma, o texto de Molière assume uma função diferente uma vez que ele se integra à criação do escritor. Sganarelle presta ajuda ao cronista para ridicularizar um político. Vale ressaltar tal mudança de postura, no que diz respeito aos textos traduzidos, mesmo que ela não tenha se transformado em hábito. Se tratássemos das orientações estrangeiras na obra de Machado de Assis, a cena de Molière seria um caso exemplar que exigiria um longo desenvolvimento. Logo seria preciso fazer referência às inúmeras citações que imbricam suas crônicas, como a seus contos e seus romances. Tampouco seria possível negligenciar, ao lado de suas referências, outras citações que ele transforma e reescreve. [...] Voltando ao médico, contra a sua vontade note-se que a cena é utilizada pelo escritor-tradutor numa situação em que o texto estrangeiro se embota em prol do trecho em que ele se insere e que ele ilustra. Mas, geralmente, mesmo após 1864, quando Machado de Assis traduz uma obra estrangeira, ele o faz conservando sua autonomia. (Massa, 1970: 25) ${ }^{\mathrm{v}}$

c) Em crônica de 2 de fevereiro de 1873, escrita para o Semana Ilustrada e assinada pelo Dr. Semana com o mesmo título do conto, aparece também como epígrafe a mesma citação de Molière, porém mais ampliada: Hippocrate dit... que nous nous couvrions tous deux. GERONTE 
Hippocratte dit cela?

SGANARELLE

Oui.

GERONTE

Dans quel chapitre, s'il vous plait?

SGANARELLE

Dans son chapitre... des chapeaux.

MOLIĖRE: Le Médecin malgré lui.

Act II, sc. III (J, p. 67, v. 24.).

d) Nos Diálogos e reflexões de um relojoeiro (1956), aparecem duas referências a essa peça de Molière. Em 1886, sob o pseudônimo de João das Regras, Machado de Assis escreveu, na Gazeta de Notícias, os diálogos, com o título de "A+B", dentre os quais (22/09) valeu-se de uma fala de Sganarello: "A Upa! Você falou agora como um doutor. Cabricias autem, como diz o médico de Molière” (MAGALHÃES JÚNIOR, 1956, p. 30). Sobre essa passagem, R. Magalhães Júnior comentou em nota de rodapé:

Machado de Assis tenta citar uma fala de Sganarello, no II ato, cena VI, de "Le Medecin (sic) Malgré Lui", mas fazendo-o de memória adultera a citação, como muitas vezes aconteceu. A moxinifada, em que o médico à força engrola o seu latinório, começa assim: "Cabricias arci thuram, catalamus, singulariter, etc." (MAGALHÃES JÚNIOR, 1956, p. 30).

Note-se que, na análise de Magalhães Júnior, a tentativa de Machado de citar uma fala da peça francesa foi considerada uma adulteração. Tal observação remete à noção tradicional da fidelidade ao texto original. Porém, de acordo com os insights sobre a tradução na pós-modernidade, tal "adulteração" é vista positivamente, como uma recriação.

e) Em Bons Dias, com o pseudônimo de "Boas Noites", Machado de Assis, a 11 de maio de 1888, utilizou-se novamente do falso médico de Molière em uma crônica que relata as discussões sobre a lei de abolição, as quais agitavam a sociedade do Segundo Império:

- Sim, senhor. Saiba que o Clapp tinha o plano feito de ir a Ouro Preto pegar os tais escravos e restitui-los aos senhores, dando-lhes ainda uma pequena indenização do seu bolsinho, e pagando ele mesmo a sua passagem da estrada de ferro. Foi por isso que...

- Mas então quem é que está doido?

- É o senhor; o senhor é que perdeu o pouco juízo que tinha. Aposto que não vê que anda alguma coisa no ar.

- Vejo; creio que é um papagaio.

- Não, senhor; é uma república. Querem ver que também não acredita que esta mudança é indispensável?

- Homem, eu, a respeito de governos, estou com Aristóteles, no capítulo dos chapéus. O melhor chapéu é o que vai bem à cabeça. Este, por ora, não vai mal. Vai pessimamente. Está saindo dos eixos; é preciso que isto seja, senão com a monarquia, ao menos com a república, aquilo que dizia o "Rio-Post" de 21 de junho do ano passado. Você sabe alemão?

- Não.

- Não sabe alemão?

E, dizendo-lhe eu outra vez que não sabia, ele imitando o médico de Molière,vi dispara-me na cara esta algaravia do diabo:

Es dürfte leicht $\mathrm{zu}$ erweisen sein, dass Brasilien weniger eine konstitutionelle Monarchie als eine absolute Oligarchie ist (MACHADO DE ASSIS apud MAGALHÃES JÚNIOR, 1956, p. 81-2).vii

Raymundo Magalhães Júnior, ao comentar essa citação em alemão, fornece informações importantes para a análise da prática tradutória desenvolvida no século XIX, à medida que evidencia que as traduções eram, em sua maioria, feitas de segunda mão, tendo como base a língua francesa:

A frase em alemão tem este significado: "Poder-se-ia demonstrar facilmente que o Brasil é menos uma monarquia constitucional do que uma oligarquia absolutista". A propósito, é interessante notar que, a partir de 1883, Machado de Assis andara estudando alemão com o professor Alexandre, juntamente com seu colega da "Gazeta de Notícias", o cearense João Capistrano de Abreu. Nas "Falenas", ao apresentar a tradução de "Os deuses da Grécia”, colocara ao pé da primeira página esta declaração: "Não sei alemão; traduzi estes versos pela tradução em prosa francesa de um dos mais conceituados intérpretes da língua de Schiller". Tal precaução não tivera, porém, ao publicar antes, nas "Crisálidas", a tradução de "As Ondinas" de Henri Heine. Em "A Semana”, na crônica de 6 de maio de 1894, citou Goethe (sic) em alemão (1956, p. 82).

Antônio Fonseca Pimentel também comentou sobre essa citação em alemão:

Em 1888, cinco anos após haver encetado aquele estudo, Machado de Assis perpetra a sua primeira citação em alemão. É na crônica de 11 de maio do aludido ano, da série "Bons Dias", quando, comentando a iminente abolição da escravatura e a eventual proclamação da república, põe na boca de um suposto interlocutor a frase em alemão, que chama de "algarávia [sic] do diabo" (PIMENTAL, 1974, p. 18). 
Pimentel cita uma série de exemplos sobre a presença da cultura alemã na obra de Machado, após 1883, dos quais destaco a tradução do Intermezzo, de Heine. Esta havia sido encomendada pelos diretores de A Semana, Valentim Magalhães e Max Fleiuss, a vários tradutores e Machado de Assis foi um deles. Como informa Pimentel, coube ao escritor a tradução do Prólogo, composto de seis oitavas, que foi publicado em 14 de abril de 1894, sendo depois enfeixada em um volume com as demais traduções. A tradução do Intermezzo teve duas edições: uma naquele mesmo ano e outra em 1902. Em nota de rodapé, Pimentel acrescenta:

Não temos à mão nenhuma das duas edições do Intermezzo de Heine em português, ambas esgotadas, para investigar se a tradução terá sido feita com base no original ou não. Pelos nomes dos tradutores [Lúcio de Mendonça, Luiz Delfino, Raul Pompéia, Afonso Celso, João Ribeiro, Gonçalves Crespo, Rodrigo Otávio, Magalhães de Azeredo, Augusto de Lima, Raimundo Correia, Fagundes Varela, Fontoura Xavier, Silva Ramos, Pedro Rabelo, Francisca Júlia da Silva, Artur Azevedo, Xavier da Silveira, Lucindo Filho, Alcides Flávio, Luiz Cunha, Luiz Rosa, Taveira Júnior, Belarmino Carneiro e o próprio Valentim Magalhães], tudo indica que não, se bem que Machado em 1894 devesse estar em condições de fazer a tradução diretamente do alemão. O Intermezzo, como se sabe, é uma das partes do Livro dos Cantos (Buch der Liede), publicado por Heine em 1827 (PIMENTEL, 1974, p. 23).

O ano de 1883 é considerado um marco histórico-literário na carreira do já "quarentão" Machado de Assis, pois, de acordo com A. Fonseca Pimentel, em A presença alemã na obra de Machado de Assis (1974), essa data é histórica porque o escritor decidiu tardiamente estudar alemão, apesar de, mesmo sem saber o idioma, já ter se interessado pela literatura dos teutos. Pimentel dividiu seu ensaio em dois momentos - antes e depois de 1883 -, para investigar "os reais e completos motivos" que levaram o escritor àquela decisão "um tanto tardia, sem dúvida, em sua vida" (1974, p. 12). Pimentel conclui seu estudo dizendo que o escritor começou a estudar alemão para não ficar defasado, pois Tobias Barreto dominava o idioma e propagava a cultura alemã no Brasil como sendo melhor que a francesa. Essa rivalidade

entre o francesismo e o alemanismo como então, não raro, se denominavam as correntes culturais francófila, tradicional, e germanófila, emergente, chegou a tal ponto que, por irrisão, se chamou a Tobias e seus seguidores de Escola teuto-sergipana e estes, em revide, apelidaram a corrente contrária de Escola galo-fluminense (PIMENTEL, 1974, p. 35).

É ainda Pimentel quem comenta:

Pois em 1900 o movimento germanista brasileiro, iniciado pelo gênio desigual, mas grandioso, de Tobias, já contava com trinta anos de atividade e havia, como se viu, produzido, entre outros, um Clóvis Bevilaqua, um Graça Aranha e um Artur Orlando. Em face de toda aquela efervescência em torno da filosofia alemã, da cultura alemã, do idioma alemão, é provável que Machado de Assis se tenha dado conta talvez mesmo com alguma ansiedade ou até dramaticidade de que haveria uma séria lacuna em sua formação cultural, que urgia preencher. E provavelmente não terá sido mero acaso que o ano em que decidiu estudar a língua de Heine, 1883, seja exatamente o mesmo em que apareciam em volume no Recife os citados Estudos alemães, publicados, na imprensa periódica, em 1881-82, e nos quais Tobias Barreto faz um verdadeiro show de seu conhecimento do alemão e da cultura alemã em geral. Segundo Francisca Basto Cordeiro [autora de Machado de Assis que eu vi, 1961] (...), o criador de Brás Cubas estudava alemão juntamente com João Ribeiro, Capistrano de Abreu e José Veríssimo, o que vem provar que havia mesmo um prurido em torno do conhecimento do idioma de Goethe espalhado pelo ar, no Brasil dos fins do século passado, principalmente por ação da Escola do Recife. Tudo leva a crer, porém, que Machado nunca chegou a ser fluente no idioma de Goethe, sendo certo, pelo menos, que jamais chegou a manejá-lo como manejava o francês e o inglês. [Vale lembrar aqui, que Machado de Assis traduziu alguns fragmentos de Oliver Twist, em 1870, a partir de uma tradução francesa]. Os seus conhecimentos a respeito deveriam ser suficientes para ler, provavelmente não raro com um dicionário à mão, e para pequenas traduções; não, todavia, para falar correntemente a língua de Schiller e Heine ou nela redigir, como fazia desembaraçadamente Tobias Barreto. É provável mesmo que, não obstante as citações feitas, a própria leitura do Fausto e outras obras de Goethe no original não lhe foi fácil. Talvez isso explique a existência em sua biblioteca particular, como o revelou Jean-Michel Massa, de traduções francesas das mesmas juntamente com os originais alemães (PIMENTEL, 1974, p. 37-39).

O que é importante nesse estudo é a questão das traduções indiretas, de "segunda mão", de textos alemães a partir de traduções francesas, efetivadas antes de 1883. Para John Gledson (1998, p. 7), as traduções devem ser feitas a partir da língua de que se originam e, por isso, o estudioso inglês não inclui as traduções dos poemas de Schiller e Heine e nem a do poeta inglês William Cowper, porque tinha certeza de que Machado não conhecia o original quando fez as traduções, o que Jean-Michel Massa já havia provado em seu Machado traducteur (1970). ${ }^{\text {viii }}$ Assim como Machado fez várias traduções indiretas, Visconde de Castilho também o fez, como mostra o próprio Machado. Aliás, esse procedimento era muito comum no século XIX, pois a segunda língua das pessoas versadas da época era o francês. Pimentel comenta que, em 1875, Machado de Assis, ao afirmar que o Visconde fôra um "tradutor exímio de Ovídio, Vergílio e Anacreonte, de Shakespeare, Goethe e Molière", teria exagerado nos elogios post mortem, porque "no que concerne a Goethe, Castilho não parece haver sido tão exímio, a julgar pela polêmica que a sua 
tradução de Fausto provocou [...]. Ademais, como foi objeto de comentário na polêmica, essa tradução foi feita de uma outra francesa e não do original" (PIMENTEL, 1974, p. 16).

Em sua trajetória literária, um dos escritores que mais acompanhou Machado pelos labirintos de suas criações foi o poeta e dramaturgo inglês, William Shakespeare. Como discípulo confesso do mestre, soube recriar com engenho e arte a obra shakespeariana, adaptando-a aos seus propósitos narrativos. Pode-se afirmar que Hamlet, Otelo, Romeu e Julieta e Macbeth foram seus textos prediletos. Citações de falas desses personagens aparecem em suas crônicas, contos, romances, enfim, disseminados pela sua obra. Porém, as referências adquirem uma roupagem machadiana com novos significados: irônicos, galhofeiros, perversos ou satânicos. Machado sempre se valia de citações de Shakespeare, ora para invertê-las, ora para questioná-las. O artigo de Sandra Vasconcelos, "Machado de Assis lê Shakespeare", ix demonstra essa técnica de apropriação, enfocando as citações de Hamlet:

Só para mencionar alguns exemplos: a expressão "To be or not to be" dá nome a um conto de 1876, enquanto que os versos "There are more things in heaven and earth, Horatio,/ Than are dreamt of in our philosophy". (Hamlet, ato I, cena 5, 11.166,167) aparecem, em geral alterados, em Quincas Borba, cap. CLXVIII ("Sem conhecer Shakespeare, ele emendou Hamlet: "Há entre o céu e a terra, Horácio, muitas coisas mais do que sonha a vossa vã filantropia) e cap. CLXIX ("D. Fernanda não entendeu esta palavra. Creio que mais, porque eu o adoro! Em verdade, a conclusão não parecia estar nas premissas; mas era o caso de emendar outra vez Hamlet: "Há entre o céu e a terra, Horácio, muitas coisas mais do que sonha a vossa vã dialética."); no conto "A Cartomante" ("Hamlet observa a Horácio que há mais cousas no céu e na terra do que sonha a nossa vã filosofia. Era a mesma explicação que dava a bela Rita ao moço Camilo, numa sexta-feira de novembro de 1869, quando este ria dela, por ter ido na véspera consultar uma cartomante; a diferença é que o fazia por outras palavras.); e em inúmeras crônicas, como as de 2 de julho de 1893 ("Esta impossibilidade de esconder o que se passa, no segredo das deliberações, faz-me crer no ocultismo. É ocasião de emendar (grifo acrescentado) Hamlet; "Há entre o Palácio do Conde dos Arcos e a rua do Ouvidor muitas bocas mais do que cuida a vossa inútil estatística"); 11 de fevereiro de 1894 ("Há duas astronomias, a do céu e a da terra; a primeira tem astros e algarismos; a segunda dispensa os astros, e fica só com os algarismos. Mas há também entre o céu e a terra, Horácio, muitas coisas mais do que sonha a vossa vã filosofia. Uma dessas coisas, como vos digo, é a vertigem dos números.”); 10 de janeiro de 1895 (“... os bookmakers, apesar do nome, nunca escreveram livros, e que há entre uma casa e outra mais frontões do que sonha a minha vã filologia."); 27 de outubro de 1895 ("Abre-se um capítulo de mistérios, de fenômenos obscuros, e concordávamos todos com Hamlet, relativamente à miséria da filosofia".); 20 de dezembro de 1896 ("Há mais coisas entre o céu e a terra do que sonha nossa vã filosofia. É velho este pensamento de Shakespeare; mas nem por velho perde.”).

Helen Caldwell amplia as referências. Quanto a Hamlet, comenta que esse personagem "aparece um pouco por contaminação - mesmo quando se está tratando dos Otelos; Ofélia, Jaques, Caliban, Lady Macbeth e outros personagens ressurgem miraculosamente nos subúrbios do Rio de Janeiro" (CALDWELL, 2000, p. 19-20). Otelo foi utilizado por Machado de Assis, segundo Caldwell, em 28 narrativas, peças e artigos. Além dessa tragédia, Romeu e Julieta serviu de enredo para um romance e dois contos. ${ }^{\mathrm{x}}$

Se a citação é um indício, uma referencialidade, uma moldura do pensamento do escritor, em que se pode detectar suas preferências literárias, como quer Compagnon (1996), então, em Memorial de Aires, tem-se o perfil do eruditismo de Machado de Assis em que o autor, apresentando-se sob a máscara do personagem Aires, põe a descoberto uma cadeia literária hipertertextual.

Memorial de Aires é um inventário da bi(bli)ografia machadiana. De acordo com Compagnon, uma bibliografia é o modelo de uma autobiografia, um scrap-book, onde entra uma coletânea de lembranças, um bilhete de trem, tíquetes de museu, programas de espetáculo, cartões de convite, flores secas: inventário dos ícones do autor [...], catálogo dos textos lidos pelo autor enquanto o projeto atual de escrita o conduz (COMPAGNON, 1996, p. 75).

No catálogo literário do diplomata, encontramos referências ao Eclesiastes, a Shelley, Thachery, Shakespeare, Goethe, Mozart, Dante, Schumann, João de Barros, João Zorro e Dom Diniz. Esse inventário dos ícones do narrador traduz a bi(bli)ografia clássica, canônica, refinada do diplomata Machado de Assis que, com grande habilidade, com arte e com diplomacia, soube tão bem inserir a literatura brasileira no contexto mundial.

Respaldado pela profissão de diplomata, o Conselheiro, em seu diário, revela ao papel todas as suas leituras, seus conhecimentos, suas impressões da vida e das pessoas, catalogando seu cânone literário/cultural. Desse catálogo, destaca-se a referência a Shelley por remeter a um conceito de tradução que avalia a liberdade de criação do tradutor. No dia 20 de janeiro de 1888, onze dias após o início da escrita do diário, o Conselheiro escreve:

Gastei o dia a folhear livros, e reli especialmente alguma coisa de Shelley e também de Thackeray. Um consoloume do outro, êste desenganou-me daquele; é assim que o engenho completa o engenho, e o espírito aprende as línguas do espírito (J, p. 21, v. 9).

Dessa leitura, o Conselheiro destaca o verso I can give not what men call love retirado da segunda estância do poema de Shelley, intitulado "To - "xi, escrito em 1821, para expressar as suas impressões sobre a viúva de nome Fidélia. Esse verso atravessa todo o diário, funcionando como um mote. O diarista apropria-se desse verso e transforma-o, ao traduzi-lo: "Assim disse comigo em inglês, mas logo depois repeti em prosa nossa a confissão do 
poeta, com um fecho da minha composição: "Eu não posso dar o que os homens chamam amor... e é pena!" (grifo acrescentado) (J, p. 26, v. 9).

Ao traduzir o verso "com um fecho" próprio, o tradutor alforria-se do poeta inglês. A apropriação modificada do verso através do acréscimo das reticências e do comentário "e é pena" coloca em cena a liberdade criativa do tradutor, transformando-o e tornando-o seu. Ao apropriar-se do verso, ao tomar posse dele, tornando-se autor/proprietário, o diplomata-tradutor desloca o texto do contexto inglês para o brasileiro ao integrá-lo às suas reminiscências literárias, chegando ao extremo de invertê-lo, pois, ao final do diário, o verso é citado da seguinte maneira: I can, etc. (J, p. 239, v. 9). A supressão do resto do verso em que se tem a negativa, apesar do etc, deixa marcada a afirmativa. $\mathrm{O}$ tradutor, em sua autoridade de autor do verso, pode transformá-lo.

Nesse sentido, o diplomata-tradutor libertou-se da servilidade e submissão ao texto primeiro, e, por meio de sua ficção e de crônicas diversas, Machado de Assis desenvolveu uma teoria da tradução, por subtração, de forma obliqua e enviesada, formando um mosaico teórico de tradução, paralelemante à sua criação literária, ao entender a importância da tradução, não apenas como um componente de sua formação intelectual, mas como da identidade cultural do país.

Com esses exemplos, pretendeu-se demonstrar o uso da citação como crítica e parte integrante da formação intelectual e literária do escritor-tradutor Machado de Assis. A tradução de fragmentos de textos estrangeiros evidencia o importante papel que a tarefa tradutória exerceu não apenas em sua carreira literária, mas também no contexto cultural da sociedade oitocentista brasileira, aflorando-se o próprio e o alheio na rede comparatista em que a tradução é peça fundamental do mosaico tradutório/intertextual machadiano.

\section{REFERÊNCIAS BIBLIOGRÁFICAS}

CALDWELL, Helen. The Brazilian Othello odf Machado de Assis: a study of Dom Casmurro. Berkeley: University of California Press, 1960.

- O Otelo brasileiro de Machado de Assis: um estudo de Dom Casmurro. Tradução de Fábio Fonseca de Melo. Cotia, SP: Ateliê Editorial, 2002.

CAMPOS, Haroldo de. Da tradução como criação e como crítica. In: ——. Metalinguagem \& outras metas: ensaios de teoria e crítica literária. 4. ed. (rev. ampl.). São Paulo: Perspectiva, 1992. p. 31-48.

CARVALHAL, Tânia F. O próprio e o alheio: ensaios de literatura comparada. São Leopoldo, RS: Ed. da UNISINOS, 2003.

CASANOVA, Pascale. A república mundial das letras. Tradução de Marina Appenzeller. São Paulo: Estação Liberdade, 2002.

COMPAGNON, Antoine. O trabalho da citação. Tradução de Cleonice P. B. Mourão. Belo Horizonte: Ed. da UFMG, 1996.

CURY, Maria Zilda F.; PAULINO, Graça; WALTY, Ivete. Intertextualidades: teoria e prática. 4.ed. Belo Horizonte: Editora Lê, 1998.

FERREIRA, Eliane F. C. Para traduzir o século XIX: Machado de Assis. São Paulo: Annablume; Rio de Janeiro: ABL, 2004.

GLEDSON, John. Machado de Assis e confrades de versos. São Paulo: Minden, 1998.

MACHADO DE ASSIS, Joaquim Maria. Obras completas de Machado de Assis. Rio de Janeiro: Jackson, 1952.

MAGALHÃES JÚNIOR, Raymundo (Org.). Diálogos e reflexões de um relojoeiro. Rio de Janeiro: Civilização Brasileira, 1956.

MASSA, Jean Michel. Machado de Assis traducteur. Tese complementar (Doutorado em Letras) - Faculté des Lettres de Poitiers, Paris, 1970. $116 \mathrm{f}$.

PIMENTEL, Antônio F. A presença alemã na obra de Machado de Assis. Rio de Janeiro: São José, 1974.

SOUZA, Eneida M. de. O espaço nômade do saber. In: Crítica cult. Belo Horizonte: Ed. da UFMG, 2002. p. 39-46.

- Tradução e intertextualidade. In: Traço crítico. Belo Horizonte: Ed. da UFMG; Rio de Janeiro: Ed. da UFRJ, 1993. p. 35-41.

Notas:

\footnotetext{
${ }^{\text {i } V e r ~ F E R R E I R A, ~ E l i a n e . ~ P a r a ~ t r a d u z i r ~ o ~ s e ́ c u l o ~ X I X: ~ M a c h a d o ~ d e ~ A s s i s . ~ S a ̃ o ~ P a u l o: ~ A n n a b l u m e ; ~ R i o ~ d e ~ J a n e i r o: ~ A B L, ~} 2004$.

${ }^{\text {ii }}$ Todas as referências à obra de Machado de Assis foram extraídas da edição da Jackson, que a partir daqui serão indicadas pela letra J, seguida da página e do volume.
} 


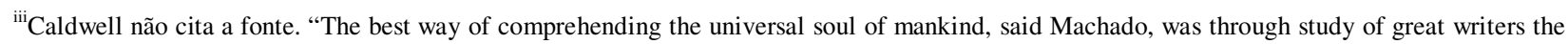
world over; the best way of portraying it was by "plagiarizing" them" (Caldwell, 1960: 165).

${ }^{i v}$ Data da tradução do livro La seconde main ou le travail de la citation (1979).

${ }^{\vee}$ Tradução de Marie-Anne Kremer: Le 14 août 1864, Machado de Assis intègre à une chronique politique la traduction du célebre dialogue entre Géronte et Sganarelle où ce dernier explique, à la lumière d'Aristote, le mutisme de Lucinde. Le texte de Molière assume alors une fonction différente puisqu'il s'intègre à la création de l'écrivain. Sganarelle vient prêter main-forte au chroniqueur pour ridiculiser un homme politique. Il paraît utile de signaler un tel chagement d'orientation à l'égard des textes traduits, même s'il ne se transforme pas en habitude. Si nous traitions les orientations étrangères dans 1 'oeuvre de Machado de Assis, la scène de Molière serait un cas exemplaire qui appellerait unlong développement. En effet à sa suite il faudrait évoquer les innombrables citations qui émaillent ses chroniques et bientôt ses contes et ses romans. De même, il ne faudrait pas négliger, à côte de ces références, d'autres citations qu'il transforme et réécrit.[...]Pour revenir au Médecin malgré lui, notons que la scène est utilisée par l'écrivain-traducteur dans une situation où le texte étranger s'émousse au profit du passage où il s'insère et qu'il illustre. Mais, généralement, même après 1864, Machado de Assis, quand il traduit une oeuvre étrangère, lui conserve son autonomie (1970: 25).

${ }^{v i}$ Sobre essa citação do médico, R. Magalhães Júnior comenta: "Sganarelle, em "Le Médecin Malgré Lui”, engana Géronte, depois de lhe fazer uma pergunta semelhante à da crônica: "Vous n'entendez point le latin?" Géronte responde: "Non". Então, Sganarelle desfecha, com entusiasmo: "Cabricias arci thuram, catalamus, singulariter, nominativo, haec musa etc."... Géronte lamenta pouco ter estudado e Jacqueline exalta a competência do doutor à força... (1956, p. 81-2).

vii Tradução literal feita por Pimentel: "Devia ser fácil provar que o Brasil é menos uma monarquia constitucional do que uma oligarquia absoluta." (1974, p. 18).

viii Em sua apresentação das traduções poéticas de Machado de Assis, John Gledson diz: "Seria difícil, mesmo para o admirador mais fanático de Machado de Assis, argumentar que ele foi um grande poeta. [...]. Este pequeno volume de traduções pode parecer, portanto, apenas um aspecto menor de um aspecto menor da sua obra. Sem dúvida é verdade, mas resulta que até essas obras, e a pequena história que espero tecer em torno delas, iluminam vertentes da sua personalidade complexa e rica. Esta é a primeira vez que esses poemas são publicados com os originais, para assim podermos apreciar a perícia do tradutor. Cumpre dizer desde já: temos uma dívida enorme com Jean-Michel Massa que, n’A juventude de Machado de Assis e no menos conhecido Machado de Assis traducteur, fornece preciosas informações que nos ajudaram no trabalho de rastrear os originais e a história da publicação dessas obras. É um assunto inesperadamente complexo: quando foram traduzidos esses textos? Machado traduziu diretamente do original ou, no caso de textos não escritos em francês, através de versões francesas? A partir do momento em que Massa descobriu que Machado lançou mão de uma tradução francesa para traduzir o Oliver Twist de Dickens, uma certa desconfiança tornou-se necessária. Aqui, publicamos só os poemas de cujo original dispomos e dos quais podemos dizer, com um mínimo de confiança, que foram usados por Machado com base para tradução. Noutros casos, intrincados demais para serem enumerados, como os poemas de Schiller, Heine, Cowper e de outros menos conhecidos, podemos ter certeza de que ele não conhecia o original quando fez a tradução. Evidentemente, pode ter havido casos intermediários - nada impede que Machado tenha utilizado outras versões, mesmo nos casos de Shakespeare e Poe" (1998: 7).

${ }^{i x}$ Este texto foi apresentado no Congresso da BRASA (Brazilian Associated Studies) realizado em Washington em 1997, e foi-me enviado por email com autorização de poder ser citado em minha tese. Aproveito a oportunidade para agradecer à Profa. Dra. Sandra Vasconcelos da USP.

${ }^{\mathrm{x}} \mathrm{Na}$ tradução, consta que a tragédia foi usada em nove contos, porém, conferindo com o original em inglês, constata-se que foram em dois contos.

${ }^{x i}$ Agradeço a Harold Bloom por ter enviado a localização desse verso na obra de Shelley. 